\title{
Artikel
}

\section{Extra beschermd of extra beschadigd?}

\author{
De juridische positie en leefomstandigheden van kinderen met een handicap in \\ asielzoekerscentra in Nederland
}

Mr. M. Goeman en mr. S. Schuitemaker*

\section{Inleiding}

'We hebben alles achtergelaten, ons huis en goede baan voor de gezondheid van mijn kind. Als het leven van mijn kind niet in gevaar was, zou ik hier geen dag blijven. Ik heb alles opgegeven voor mijn kind. Alle ouders zouden dat begrijpen. Ik had daar controle over mijn eigen leven, nu heb ik over niks controle en wordt er voor mij beslist.'

(Een vader in een asielzoekerscentrum met een kind met een handicap).

Naar aanleiding van het stijgende aantal vragen en signalen op de Kinderrechtenhelpdesk ${ }^{1}$ over kinderen met een handicap in asielzoekerscentra, heeft Defence for Children door middel van dossieranalyse en een veldonderzoek onderzocht of het Internationaal Verdrag inzake de rechten van het kind (VN-Kinderrechtenverdrag) en het Verdrag inzake de rechten van personen met een handicap (VN-verdrag Handicap) ${ }^{2}$ nageleefd

* Mr. M. (Martine) Goeman is Programmamanager kinderrechten en migratie. Mr. S. (Sander) Schuitemaker is Juridisch adviseur kinderrechten en migratie bij Defence for Children.

1. De Kinderrechtenhelpdesk is het kloppende hart van Defence for Children. Dagelijks wordt telefonisch en per e-mail antwoord gegeven op vragen over kinderrechten - vragen van advocaten, hulpverleners, ouders en kinderen zelf. Jaarlijks worden zo'n 1.100 vragen over kinderrechten en jeugdrecht, uitbuiting en migratie beantwoord.

2. Voor de definitie van het begrip 'handicap' is in het onderzoek aangesloten bij de definitie uit artikel 1 VN-verdrag Handicap: 'Personen met een handicap omvat personen met langdurige fysieke, mentale, intellectuele of zintuiglijke beperkingen die hen in wisselwerking met diverse worden binnen de verblijfsrechtelijke procedure van kinderen met een handicap en bij de opvang van deze kinderen in asielzoekerscentra. Voor het onderzoek zijn 57 zaken geanalyseerd en zijn bij het veldonderzoek twaalf kinderen en jongeren betrokken in de leeftijd van 7 maanden tot en met 21 jaar. Daarnaast zijn zestien ouders geïnterviewd en verschillende professionals. De kinderen waren afkomstig uit Afghanistan, Albanië, Armenië, Azerbeidzjan, Congo, Irak en Rusland. Voorbeelden van aandoeningen die kinderen in asielzoekerscentra hebben, zijn Duchenne spierdystrofie, cerebrale parese, epilepsie die niet met medicijnen behandeld kan worden, stofwisselingsziekten, groeistoornissen, scoliose, zeer ernstige neurologische aandoeningen, sikkelcelanemie met complicaties en het syndroom van Down. ${ }^{3}$ Aan de hand van drie zaken van onze Kinderrechtenhelpdesk illustreren wij in dit artikel de problemen waar kinderen met een handicap in asielzoekerscentra tegenaan lopen en wordt een samenvatting gegeven van de onderzoeksresultaten. ${ }^{4}$ We bespreken daarbij ook een recent vernietigend rapport van de Kinderombudsman over medische zorg die aan een doof meisje werd geweigerd omdat zij geen verblijfsvergunning had. We beto-

drempels kunnen beletten volledig, effectief en op voet van gelijkheid met anderen te participeren in de samenleving.'

3. Duchenne spierdystrofie is een ernstige erfelijke spierziekte die de spieren aantast en verzwakt. Bij cerebrale parese zijn de hersenen niet in staat de juiste spanning aan de spieren door te geven en ze onderling op de goede manier te laten samenwerken. Cerebrale parese ontstaat vaak in de zwangerschap.

4. M. Goeman, S. Schuitemaker, Extra beschermd of extra beschadigd? Onderzoek naar de leefomstandigheden van kinderen met een handicap in asielzoekerscentra in Nederland, Defence for Children 2018, ISBN 978-90-74270-41-0. Het volledige onderzoek is beschikbaar via: www.defenceforchildren.nl. 
gen dat de wetgever, de immigratieautoriteiten en de opvanginstanties aan zet zijn om ervoor te zorgen dat de rechten van kinderen met een handicap gerespecteerd worden. Zowel in de verblijfsprocedure als de opvangprocedures en de toegang tot medische zorg. Immigratieautoriteiten en opvanginstanties dienen zo snel mogelijk samen met zorgaanbieders een richtlijn voor afstemming in de uitvoering op te stellen voor de zorg voor kinderen die (nog) geen verblijfsvergunning hebben.

\section{De (on)mogelijkheden van de verblijfsprocedure}

Uit de analyse van de 57 helpdeskzaken blijkt dat kinderen met een handicap verschillende verblijfsrechtelijke procedures volgen. $\mathrm{Zij}$ zoeken bescherming via de medische procedure, de asielprocedure of via een procedure waarin een beroep kan worden gedaan op hun schrijnende situatie. Verblijfsprocedures van kinderen met een handicap duren helaas vaak vele jaren. Hieronder geven we een voorbeeld van een schrijnende situatie. We zijn ook bekend met een aantal zaken waar het kind gedurende de procedure overleed.

E. lijdt aan spierdystrofie (type Duchenne) met een ernstige hartafwijking. Gedurende de ziekte is er een toenemende zwakte van de armspieren, de rugspieren en de hartspier. Dit leidt tot vergroeien van de wervelkolom (scoliose) en toenemende afhankelijkheid van verzorgers. Daarnaast is beademing nodig. Toen de artsen $\mathrm{E}$. voor het eerst zagen in 2009 was E. in staat korte afstanden te lopen. Als de zaak in 2016 bekend wordt bij Defence for Children is hij volledig rolstoelgebonden. E. is volledig van verzorging afhankelijk voor Algemene Dagelijkse Levensverrichtingen (ADL). In 2010 is bij E. progressieve verminderde werking van de hartspier vastgesteld (cardiomyopathie) waarvoor hij medicatie krijgt. Wegens ernstige benauwdheid (verminderde longfunctie) werd hij 's nachts thuis beademd. In 2016 is gestart met sondevoeding wegens ondergewicht. E. wordt twee keer per jaar gezien door een multidisciplinair team van een kinderziekenhuis. Bij problemen vaker. Daarnaast is hij onder behandeling van een kinderarts en diëtiste.

Als medische behandeling uitblijft, ontstaat vrijwel direct een medische noodsituatie en zal E. snel overlijden. In 2012 hebben E. en zijn moeder korte tijd in vreemdelingendetentie gezeten om te worden uitgezet naar hun land van herkomst. De detentie is opgeheven omdat E. niet fit-to-fly werd verklaard door de keuringsarts. In 2014 is aan E. uitstel van vertrek verleend omdat thuis- beademing niet mogelijk was in het land van herkomst volgens Bureau Medische Advisering (BMA), dat de staatssecretaris adviseert over de medische situatie en de behandelmogelijkheden in het land van herkomst.

Naast een medische aanvraag werd een aanvraag op grond van het kinderpardon gedaan. ${ }^{5}$ Deze aanvraag werd afgewezen omdat de moeder onvoldoende meegewerkt zou hebben aan terugkeer naar het land van herkomst. Volgens de behandelaars van het kinderziekenhuis kunnen patiënten met Duchenne in Nederland met de behandelmethoden 30 of soms 40 jaar oud worden; zonder deze behandeling is het behalen van de volwassen leeftijd niet waarschijnlijk. $\mathrm{Na}$ eerder uitstel van vertrek in 2014 heeft de IND zich in 2017 op advies van het BMA op het standpunt gesteld dat behandeling nu wel mogelijk zou zijn in een privéziekenhuis in het land van herkomst. Dit zou echter onbetaalbaar zijn. In beroep houdt de staatssecretaris vol dat behandeling mogelijk zou zijn in de eerder genoemde privékliniek.

Uit een mail die na veel aandringen wordt verkregen door de advocaat van $E$. schrijft de directeur van het beoogde privéziekenhuis dat de multidisciplinaire zorg die nodig is niet kan worden geboden. De thuisbeademing en behandeling die E. in een gespecialiseerd ziekenhuis nodig heeft, is eveneens niet mogelijk, zo schrijft het ziekenhuis. De IND wilde het BMA deze nieuwe informatie laten beoordelen en vroeg de rechtbank de beroepszaak aan te houden. De rechtbank honoreerde dit verzoek.

In 2018, negen jaar na aankomst in Nederland, verleende de staatssecretaris op grond van zijn discretionaire bevoegdheid, in afwijking van het beleid, een verblijfsvergunning aan E. en zijn moeder.

\section{Schrijnende gevallen en artikel 3 EVRM}

In de asielprocedure en medische procedure heeft een kind met een handicap bijna geen kans op verblijfsrecht, ondanks dat de situatie geregeld heel schrijnend is. Het hebben van een (ernstige) handicap wordt niet gezien als reden om een asielvergunning te verlenen. ${ }^{6}$

5. Definitieve Regeling Langdurig Verblijvende Kinderen (DRLVK), WBV 2013/1, Stcrt. 2013, 2573, 31 januari 2013.

6. Slechts in zeer uitzonderlijke gevallen wordt besloten tot uitstel van vertrek op grond van art. 64 VW 2000 en om niet tot uitzetting over te gaan op grond van de medische situatie. Zie hierover EHRM (Grote kamer) 13 december 2016, 41738/10 (Paposhvili - België), JV 2017/22 m.nt. B.E.P. Myjer en verder o.m. ABRvS 28 september 2017, 201702168/1/V3, r.o. 6.3 . 
In bijzondere gevallen mogen mensen met medische klachten die geen verblijfsrecht hebben niet worden uitgezet, omdat zij anders in een situatie worden gebracht die onmenselijk is of die afbreuk doet aan hun menselijke waardigheid. Een dergelijke situatie doet zich alleen voor als de medische omstandigheden zeer ernstig zijn en er geen medische voorzieningen en sociale opvang aanwezig zijn in het land waarnaar wordt uitgezet. Dit volgt uit artikel 3 van het Europees Verdrag voor de Rechten van de Mens (EVRM) en uit vaste rechtspraak van het Europees Hof voor de Rechten van de Mens.

Volgens de Afdeling bestuursrechtspraak van de Raad van State vallen alleen ziekten die naar alle waarschijnlijkheid op korte termijn leiden tot het overlijden van de betrokkene, een (vrijwel) volledig verlies van Algemene Dagelijkse Levensverrichtingen, verlies van zelfstandigheid of een gedwongen opname in een psychiatrisch ziekenhuis, onder de reikwijdte van artikel 3 EVRM. Andere ziekten waarbij sprake is van een ernstige, snelle en onomkeerbare achteruitgang van de gezondheidssituatie, resulterend in intens lijden of een significante vermindering van de levensverwachting, vallen niet binnen het toepassingsbereik.

Ten tijde van ons onderzoek was er nog de mogelijkheid van de staatssecretaris van Justitie en Veiligheid om in schrijnende zaken toch een verblijfsvergunning te verlenen op basis van zijn discretionaire bevoegdheid. Er zijn verschillende zaken bij ons bekend waarbij deze bevoegdheid tot een oplossing leidde voor het kind. De discretionaire bevoegdheid is echter opgeheven nadat de afsluitingsregeling van het kinderpardon er kwam. Op 19 september 2016 is een initiatiefwetsvoorstel tot wijziging van de Vreemdelingenwet 2000 ingediend. Dit wetsvoorstel heeft tot doel om het belang van het kind, op basis van artikel $3 \mathrm{VN}$-Kinderrechtenverdrag, te verankeren en nader uit te werken in de Vreemdelingenwet 2000. Het wijzigingsvoorstel en de memorie van toelichting zijn inmiddels medio 2019 aangepast en aangescherpt, na onder andere advies van de Raad van State, en het zal dus nog wel enige tijd duren voordat de parlementaire behandeling is afgerond en het kracht van wet krijgt. $^{8}$

Hoe kunnen kinderen met een (ernstige) handicap tot die tijd hun recht halen?

\section{Uitstel van vertrek}

Zoals eerder aangegeven mag op grond van artikel 64 VW 2000 een gezin niet worden uitgezet als het van-

7. EHRM (Grote kamer) 13 december 2016, 41738/10 (Paposhvili - België), JV 2017/22 m.nt. B.E.P. Myjer. Slechts in zeer bijzondere omstandigheden neemt het EHRM aan dat een ernstig zieke vreemdeling niet mag worden uitgezet. In zijn annotatie omschrijft voormalig Nederlandse rechter bij het EHRM Myjer het als volgt: 'De terughoudendheid van het Hof bij medisch asiel is niet onlogisch. Het is nu eenmaal irreëel te veronderstellen dat Europa via het EVRM wel even alle ernstige gezondheidsproblemen van de rest van de wereld kan oplossen.'

8. Kamerstukken /I 2015/16, 34541, 6 en Kamerstukken /I 2018/19, $34541,10$. wege de gezondheidstoestand van de vreemdeling of van een van de gezinsleden niet verantwoord is om te reizen. Dit wordt ook wel 'uitstel van vertrek' genoemd. Uitstel van vertrek levert rechtmatig verblijf op (iemand wordt niet uitgezet), maar betekent geen recht op een verblijfsvergunning en brengt geen recht op een normale woning met zich mee. Wanneer uitstel van vertrek wordt verleend, blijven kinderen dus in asielzoekerscentra of vrijheidsbeperkende locaties wonen met een sober regime.

\section{Verblijfsvergunning op grond van medische redenen: een onneembare horde}

Naast uitstel van vertrek kan een verblijfsvergunning op grond van medische redenen worden verleend als een medische behandeling noodzakelijk is. De IND laat zich hiervoor adviseren door het Bureau Medische Advisering (BMA). De medische behandeling moet in Nederland worden voortgezet wanneer het BMA concludeert dat:

- in het herkomstland geen of onvoldoende behandelmogelijkheden zijn;

- $\quad$ in het herkomstland onderbrekingen in de medicijnvoorraden voorkomen, die een maand of langer duren;

- het BMA vanwege de situatie in het herkomstland niet in staat is om te adviseren over de aanwezigheid van behandelmogelijkheden;

- mantelzorg noodzakelijk is voor het slagen van de medische behandeling en in het herkomstland geen gezins- of familieleden aanwezig zijn die in staat zijn de medisch noodzakelijke mantelzorg te verlenen.

Een medische behandeling wordt als noodzakelijk beschouwd wanneer er zonder behandeling binnen drie maanden een medische noodsituatie zal ontstaan, als er geen behandelmogelijkheden zijn in het land van herkomst of als een vreemdeling niet in staat is om te reizen. $^{9}$

In het Nederlandse beleid wordt onder een medische noodsituatie verstaan:

'De situatie waarbij betrokkene lijdt aan een stoornis, waarvan op basis van de huidige medisch-wetenschappelijke inzichten vast staat dat het achterwege blijven van behandeling op korte termijn zal leiden tot overlijden, invaliditeit of een andere vorm van ernstige geestelijke of lichamelijke schade. ${ }^{10}$

Wanneer geen medische noodsituatie wordt aangenomen, wordt geen nader onderzoek verricht naar de

9. Art. 64 VW 2000, art. 3.46 Vreemdelingenbesluit 2000 en art. A3/7 Vreemdelingencirculaire 2000

10. Art. A3/7.1.3. Vreemdelingencirculaire 2000. 
behandelmogelijkheden in het land van herkomst. Kinderen en hun ouders kunnen geen geslaagd beroep doen op hun medische situatie. Er moet sprake zijn van een noodzakelijke medische behandeling, én Nederland dient naar het oordeel van de minister het meest aangewezen land te zijn voor de medische behandeling.

De IND kent vrijwel nooit een verblijfsvergunning toe aan kinderen met een handicap vanwege medische redenen. Er is geen speciaal toetsingskader voor kinderen om te bepalen of er voor hen een medische noodtoestand ontstaat bij terugkeer. Het BMA acht behandeling in het land van herkomst bijna altijd mogelijk. Er wordt niet gekeken of de zorg daadwerkelijk beschikbaar is voor kinderen. Slechts wordt gekeken naar theoretische beschikbaarheid gebaseerd op informatie van verzekeraars. Er wordt niet gekeken of ouders de zorg of medicijnen kunnen betalen, of er een sociaal of familienetwerk in het herkomstland aanwezig is, of naar de afstand die de vreemdeling moet afleggen om de noodzakelijke medische behandeling te krijgen. Uit het beleid van de IND volgt dat de bewijslast volledig op de vreemdeling rust om aan te tonen dat de vreemdeling geen toegang zal hebben tot de vereiste medische zorg. ${ }^{11}$ De afgelopen jaren hebben artsen en de Inspectie Gezondheidszorg en Jeugd regelmatig kritiek geuit op de werkwijze van het BMA. ${ }^{12}$

Kinderartsen, kinderpsychologen en deskundigen hebben gewezen op het gevaar dat kinderen schade zullen oplopen omdat de criteria die door de IND worden gehanteerd om te spreken van een medisch psychiatrische noodsituatie ongeschikt zijn voor kinderen, als gevolg waarvan ernstige schade te verwachten is. Het BMA gaat met het toepassen van criteria die gelden voor volwassenen op kinderen, voorbij aan andere factoren die ernstige schade voor de psychische en lichamelijke ontwikkeling van kinderen met zich meebrengen. Volgens deskundigen kan een medisch psychiatrische noodsituatie bij kinderen alleen worden ingeschat in combinatie met het te verwachten vermogen van de ouders om probleemgedrag van hun kind te kunnen opvangen in stressvolle omstandigheden. ${ }^{13}$ In de zaken die wij onderzochten zien we de weging van het belang van het kind niet kenbaar terug.

\section{Toegang tot zorg geweigerd of belemmerd}

Ewa (fictieve naam) is 1 jaar als ze met haar ouders uit Afghanistan naar Nederland vlucht. Hier blijkt dat zij doof is. $\mathrm{Na}$ onderzoek in het ziekenhuis blijkt dat ze geschikt is voor speciale gehoorimplantaten waarmee ze kan leren horen en spreken. Hoe jonger deze geplaatst worden, hoe beter. Toch besluit het ziekenhuis dat zij deze Cochleaire Implantaten (CI) niet krijgt. De ouders van Ewa vragen tevergeefs aan het ministerie van Justitie en Veiligheid of dat de kosten voor de implantaten wil betalen. De Kinderrechtenhelpdesk van Defence for Children ondersteunt zowel de verblijfsprocedure van Ewa als de procedure rond de toegang tot zorg voor haar. Als Ewa 5 jaar is en nog steeds geen implantaten heeft, dient haar advocaat twee klachten in bij de Kinderombudsman. De klachten zijn dat het ziekenhuis ten onrechte heeft besloten dat Ewa op eenjarige leeftijd geen implantaten kreeg. En dat de betrokken partijen uit de vreemdelingenketen niet genoeg hebben gedaan om samen met het ziekenhuis, Ewa en haar ouders te praten over een oplossing.

$\mathrm{Na}$ uitgebreid onderzoek ${ }^{14}$ concludeert de Kinderombudsman dat beide klachten gegrond zijn: 'Het ziekenhuis, het ministerie van Justitie en Veiligheid en de andere partijen uit de vreemdelingenketen hebben niet gehandeld in het belang van Ewa. Voor haar ontwikkeling en gezondheid had zij de implantaten zo jong mogelijk moeten krijgen. Dat is niet gebeurd, omdat de belangen van het ziekenhuis en het ministerie voorop stonden en zij niet geprobeerd hebben om samen een oplossing te vinden.'

Om te zorgen dat geen kind meer hoeft mee te maken wat Ewa heeft meegemaakt, wil de Kinderombudsman dat het ziekenhuis en het ministerie samen met andere organisaties voor gezondheidszorg en vreemdelingenrecht een richtlijn opstellen. Daarin moet staan hoe de zorg voor kinderen die (nog) geen verblijfsvergunning hebben geregeld wordt en hoe je daarover met elkaar in gesprek gaat. Er mag er geen onderscheid gemaakt worden tussen de zorg voor kinderen met of zonder verblijfsrecht. Ook moet er altijd een goede belangenafweging worden gemaakt, waarbij de belangen van het kind en andere belangen apart in kaart worden gebracht en de belangen van het kind zwaarwegend zijn. Vorig jaar heeft Ewa een verblijfsvergunning gekregen, maar ze is inmiddels te oud om direct twee gehoorimplantaten te krijgen. Nu één implantaat is geplaatst, moet eerst blijken of dat goed gaat en pas dan krijgt ze misschien een tweede. De kans is groot dat ze niet of niet goed genoeg meer leert horen en spreken.
14. Kinderombudsman 2019, Waar geen wil is, is geen weg, https://www. dekinderombudsman.nl/nieuws/kind-klem-tussen-gezondheidszorg-envreemdelingenrecht. Zie over dit rapport ook onze bespreking in Asiel\& Migrantenrecht 2019, nr. 9. 
Sommige ouders die wij spraken kwamen specifiek voor de zorg van hun kind naar Nederland. In andere gevallen werd in Nederland ontdekt dat het kind een bepaalde ziekte of handicap had. $\mathrm{Na}$ verblijf in Nederland met de daarbij horende zorg, willen de ouders niet meer dat hun kind (opnieuw) wordt blootgesteld aan de gezondheidsrisico's bij terugkeer. Veel ouders vertelden ons dat ze zouden willen terugkeren naar het land van herkomst, maar dat deze keuze gezien de gezondheid of de handicap van hun kind geen optie is.

In artikel $23 \mathrm{VN}-\mathrm{Kinderrechtenverdrag}$ is het recht van een kind met een handicap op bijzondere zorg neergelegd. Het kind dient een volwaardig leven te kunnen leiden in omstandigheden die de waardigheid van het kind verzekeren, de zelfstandigheid bevorderen en de actieve participatie in de maatschappij vergemakkelijken. In artikel $24 \mathrm{VN}$-Kinderrechtenverdrag staat dat elk kind recht heeft op de best mogelijke gezondheid. De overheid dient ervoor te zorgen dat geen enkel kind de toegang tot deze voorzieningen wordt onthouden. Daarnaast geldt artikel 2 VN-Kinderrechtenverdrag: het non-discriminatiebeginsel bepaalt dat kinderen zonder verblijfsvergunning recht hebben op dezelfde rechten als Nederlandse kinderen of kinderen met een verblijfsvergunning.

Zoals het voorbeeld van Ewa laat zien, is de toegang tot zorg zonder discriminatie niet gegarandeerd in Nederland. Helaas is de zaak van Ewa niet uniek. Op de Kinderrechtenhelpdesk zijn ook andere zaken bekend waarbij het recht op zorg wordt geweigerd aan een kind zonder verblijfsvergunning.

\section{Continuïteit van zorg in het geding}

Kinderen in asielzoekerscentra moeten vaak verhuizen. Hierdoor gaat kostbare informatie over de zorg verloren, ook moet opnieuw een vertrouwensrelatie met een nieuwe arts worden opgebouwd. De overdracht van zorg gaat vaak niet goed, waardoor het langer duurt voordat de behandeling weer verder kan gaan. In het kader van ons onderzoek spraken wij verschillende gezinnen waarbij de overdracht van zorg nog niet goed was geregeld na een verhuizing naar een andere gemeente. ${ }^{15}$ Zo zou een meisje een elektrische rolstoel en een soort spraakcomputer krijgen. Nadat zij moest verhuizen naar een andere gemeente, moest alles weer opnieuw worden geregeld.

15. Dit blijkt uit drie interviews; Rodrigues en Van der Meer signaleren dit probleem reeds in 2012 ook, zie: P. Rodrigues, S. Spronk-van der Meer, 'Gezinslocaties en het recht op gezondheid van minderjarige vreemdelingen', A\&MR 2012, nr. 10

\section{Opvang van kinderen met een handicap in asielzoekerscentra}

Uit een uitzending van RTL Nieuws komt de volgende casus.

Behandelaars en hulpverleners van Veilig Thuis en zorginstelling de Amerpoort dringen aan op een betere plek voor Zuzu (met het syndroom van Down), zijn moeder en zijn broer. Zijn broer is door de gespannen situatie op het kamertje tijdelijk noodgedwongen in een crisisopvang geplaatst. 'Het klopt dat de woonsituatie van de familie niet voldoet aan wat Zuzu nodig heeft om zich te ontwikkelen. Om tot een oplossing te komen is een veilige plek van belang', zegt Veilig Thuis Utrecht in een schriftelijke toelichting aan RTL Nieuws.

Kinderen van asielzoekers met een ernstige ziekte of handicap hebben zwaar te lijden onder de woonomstandigheden in asielzoekerscentra. Dat zeggen hulpverleners, artsen en vertrouwenspersonen tegen RTL Nieuws.

Burgemeester Bolsius van Amersfoort is betrokken bij de zaak en heeft staatssecretaris Harbers gevraagd gebruik te maken van zijn discretionaire bevoegdheid om het gezin een status te geven. Ook dringt de burgemeester aan op verbetering van de woonomstandigheden van $\mathrm{Zuzu}$, zijn broer en zijn moeder en van Qiyas (een jongen met epilepsie en een zusje met het syndroom van Down) en zijn gezin. Na de uitzending van RTL wordt een andere woning aangeboden die nog slechter is dan de huidige woning. Pas nadat de burgemeester een overleg bijeenroept met professionals en zorgdeskundigen over de twee kinderen komt er andere huisvesting voor hen, een appartement in het asielzoekerscentrum met meer ruimte. ${ }^{16}$

De meeste gezinnen die betrokken waren bij ons onderzoek verbleven in een vrijheidsbeperkende gezinslocatie. Dit is een locatie voor gezinnen waarvan de autoriteiten vinden dat zij terug moeten keren naar het land van herkomst. Sinds 2011 kent Nederland deze gezinslocaties. Ze verschillen van AZC's, omdat het regime vrijheidsbeperkend is en de opvangvoorzieningen sober zijn. ${ }^{17}$ Gezinnen in de gezinslocaties krijgen vrijheidsbeper-

16. RTL Nieuws, 4 april 2018.

17. De oprichting van de gezinslocaties, wanneer er kan worden overgeplaatst of wanneer opvang in een gezinslocatie kan worden beëindigd is niet in of krachtens een wet geregeld. De gezinslocaties zijn in 2011 bij 
kende maatregel opgelegd in combinatie met een dagelijkse meldplicht. ${ }^{18}$ De beperking van de vrijheid houdt in dat de gemeentegrenzen van de gemeente waar de gezinslocatie zich bevindt niet mogen worden overschreden. De soberheid blijkt vooral uit het voorzieningenniveau, de inrichting en het lagere leefgeld voor bewoners van de gezinslocaties. Er zijn veel verschillen tussen opvanglocaties. Sommige bewoners wonen in oudere gebouwen, andere in lage flats of prefabhuisjes of caravans. In sommige locaties hebben gezinnen een eigen woonruimte met keuken, douche en toilet. Elders delen gezinnen hun woonruimte en/of voorzieningen met niet-gezinsleden. In al onze gesprekken kwamen problemen met de huisvesting aan de orde. Gebreken met de hygiëne werden zowel geconstateerd in reguliere AZC's als in gezinslocaties. Problemen die voortkwamen uit het moeten delen van een woning met een ander gezin betreffen voornamelijk de gezinslocaties. Klachten over geluidsoverlast en drukke en volle locaties werden geconstateerd bij beide vormen van opvang. Zowel in de gezinslocaties als in reguliere AZC's is sprake van strenge huisregels en handhaving, waarbij bewoners gekort kunnen worden op hun leefgeld bij overtreding van de regels; voor bewoners van de gezinslocatie heeft een dergelijke strafkorting op het toch al lagere leefgeld extra impact. ${ }^{19}$

In 2018 verscheen het onderzoek 'Leefomstandigheden van kinderen in asielzoekerscentra en gezinslocaties'. Uit dit onderzoek, dat is uitgevoerd in opdracht van het Centraal Orgaan opvang asielzoekers (COA) en de Werkgroep Kind in azc, blijkt dat kinderen en ouders zich in gezinslocaties onveiliger voelen dan in asielzoekerscentra. Kinderen en jongeren in gezinslocaties spreken ook meer over pesten. ${ }^{20}$

In antwoord op Kamervragen naar de geschiktheid van asielzoekerscentra voor de opvang van ernstig zieken en mensen met een beperking antwoordt toenmalig staatssecretaris Harbers van Justitie en Veiligheid dat de opvangvoorzieningen van het COA erop zijn ingericht om asielzoekers zo goed mogelijk op te vangen. Het COA kent volgens hem speciale woonunits die geschikt en ingericht zijn voor mindervaliden. Verder hebben vluchtelingen- en migrantenkinderen recht op vergelijkbare medische zorg als ingezetenen van Nederland. ${ }^{21}$

\section{Veldonderzoek}

Defence for Children is zowel bij mensen geweest die in een speciale woonunit voor mindervaliden zaten als bij mensen die niet in een speciale woonunit verbleven. Bij

brief van minister Leers in het leven geroepen (Kamerstukken II 2011/12, 29344, 85).

18. Het gaat om een vrijheidsbeperkende maatregel op grond van art. 56 VW 2000 en een meldplicht op grond van art. 54 VW 2000.

19. 'De gezinslocaties in Gilze Rijen en Katwijk: geen plek voor een kind', Quickscan, Defence for Children/Unicef december 2011, p. 4

20. 'Leefomstandigheden van kinderen in asielzoekerscentra en gezinslocaties', Werkgroep Kind in azc en COA, 2018.

21. Kamerstukken // 2017/18, 2017 D28274. een aantal kinderen hebben we zelf kunnen waarnemen dat de woning niet voldoet. Bijvoorbeeld gezien de krapte, zeer verouderde omstandigheden of gezien de mogelijk gevaarlijke situaties die zich kunnen voordoen. De medische indicaties lijken vaak niet doorslaggevend voor de grootte van de kamer. Tijdens onze bezoeken aan opvanglocaties stonden de kamers vaak vol met spullen als tilliften en rolstoelen. Behandelaars geven geregeld bij het COA aan dat de ruimtes waarin de kinderen verblijven medisch onverantwoord zijn. Een aantal voorbeelden:

Een jongen van tien met een verstandelijke en lichamelijke handicap maakt gebruik van een badstoel en een verhoogd toilet. Zijn badstoel is van plastic en is kapot. De handvatten blijken te zijn ingescheurd. De jongen is zwaar voor zijn leeftijd en weegt 59 kilo. ${ }^{22}$ Als hij zich vasthoudt aan de stoel om op te staan, kan de stoel dit niet aan. Beide ouders moeten hem helpen bij het douchen. Het gezin wacht al meer dan een jaar op een aanpassing en verbetering. Ze hebben gevraagd om metalen beugels, zo vertelt de aanwezige gezinscoach, maar hiervan hebben ze nog niks gehoord.

Een moeder vertelt dat er sinds de verhuizing naar een ander AZC geen ruimte is in de slaapkamer voor een speciaal bed, dat eigenlijk was besteld voor haar dochter. De moeder geeft bovendien aan dat het tillen van haar dochter te zwaar voor haar wordt, waardoor ze rugproblemen krijgt. Er is ook geen speciale stoel voor haar dochter waarmee gedoucht kan worden. Nu moet dat met een gewone stoel. Dat is onveilig, want daar zou ze zomaar van af kunnen glijden. In het vorige AZC was een speciale stoel aangevraagd, maar die laat nu op zich wachten.

Een moeder vertelt: 'Wanneer mijn zoon moet douchen, moet hij eerst op bed worden uitgekleed en daarna in de douchestoel worden gezet. Hij moet dan naakt door de kamer. Wanneer het andere gezin [in de gedeelde woning] met visite zat, is dat heel ongemakkelijk. Dan moest ik vragen of zij allemaal even naar de andere kamer wilden gaan.'

De kamers in AZC's zijn vaak onhygiënisch. Kinderen komen met veel mensen in aanraking. Voor kinderen die als gevolg van hun conditie gevoelig zijn voor infecties brengt dit extra gevaren met zich mee. Ook het delen van toiletten is soms medisch onverantwoord en behandelaars geven dit in voorkomende gevallen aan. Een kinderarts beschrijft zijn zorgen in een artikel in het tijdschrift voor artsen Medisch Contact:

'Ongekend voor Nederland zou je zeggen, maar hygiene is hier een groot probleem. Het hele gebouw maakt gebruik van hetzelfde toilet en dezelfde douche, die veel bewoners niet schoon achterlaten. Voor het meisje vormt dit vanwege haar afweer-onderdrukkende medicatie een substantieel risico. Naast het infectierisico door de gebrekkige hygiëne blijkt

Een gemiddeld kind van zijn leeftijd weegt tussen de 30 en 40 kilo. 
dat ze in het huis ook gepest wordt vanwege haar uiterlijk.'23

Een zusje van een meisje met nier- en blaasproblemen vertelt dat het door de klachten van haar zusje extra belangrijk is om een schone wc te hebben. 'In het AZC hadden we één wc voor twintig gezinnen. Dat ging echt niet daarom ging mijn zusje bijna anderhalf jaar op een emmer in de kamer. We hebben wel vijf keer gevraagd of we een eigen wc konden krijgen maar dat mocht niet. De uroloog schrok ontzettend toen hij dit hoorde.'

\section{Huisregels COA}

Het COA hanteert huisregels in het AZC en voert kamercontroles uit. We komen een aantal keer tegen dat een gezin zelf een stoel heeft aangeschaft omdat het kind op een standaardstoel niet zelfstandig kon zitten. Van het COA krijgen mensen te horen dat deze meubelen in strijd zijn met de voorschriften. Ook wordt kookgerei, zoals magnetrons en blenders die nodig zijn om speciaal voedsel voor de kinderen te bereiden, verboden. De gezinnen krijgen te maken met sancties en worden gekort op hun leefgeld als dergelijke gebruiksvoorwerpen worden aangetroffen.

Een moeder die wij spraken vertelt dat haar zoon met zware verstandelijke en lichamelijke beperkingen een tapijt nodig heeft om op te kunnen liggen en te spelen. Mevrouw heeft een blender nodig om het eten van haar zoon te kunnen pureren. $\mathrm{Zij}$ geeft aan zo wanhopig te zijn geworden van alle verboden dat ze heeft gezegd niet meer verder te willen leven. Moeder heeft toen psychologische zorg gekregen en antidepressiva. Moeder wil stoppen met deze medicijnen omdat ze niet helpen en niet goed zijn voor haar bloeddruk. Daarnaast moet zij 24 uur per dag beschikbaar zijn voor haar zoon. Sinds een aantal maanden is er een uitzondering voor mevrouw en haar zoon gemaakt en sindsdien mogen zij deze faciliteiten weer op hun kamer hebben.

Een aantal gezinnen geeft aan dat de standaarddekens die door het COA worden uitgedeeld voor huidirritatie zorgen bij de kinderen, omdat het gaat om synthetische dekens. Dekens die de ouders zelf aanschaffen worden afgepakt of het COA verbiedt hen om andere dekens aan te schaffen.

Ouders mogen niet werken en moeten voor de aanschaf van dagelijkse hulpmiddelen toestemming vragen. Een aantal ouders die wij spraken gaf aan moeite te hebben met de afhankelijkheid die ze ten opzichte van het COA hebben.

De kinderen die wel een verblijfsvergunning krijgen, moeten vaak lang wachten op een woning nadat de verblijfsstatus is verleend. Voor kinderen die op grond van een zeer ernstig ziektebeeld of beperking een verblijfsvergunning krijgen en die een lage levensverwachting hebben, duurt dit veel te lang. De doorstroming naar een woning voor deze groep moet sneller zodat de kinderen de zorg en leefomgeving kunnen ontvangen waar zij recht op hebben. Meer nog dan andere kinderen kunnen zij zich simpelweg niet permitteren om zo lang te wachten.

Bij geen van de gezinnen die wij hebben onderzocht werd gebruik gemaakt van de mogelijkheden om te zorgen voor opvang buiten het AZC.

\section{Conclusie}

Helaas hebben wij moeten concluderen dat de rechten van kinderen met een handicap in asielzoekerscentra onvoldoende gerespecteerd worden. De belangrijkste knelpunten zijn dat er vrijwel nooit een verblijfsvergunning aan kinderen met een handicap wordt toegekend vanwege medische redenen. Er is geen speciaal toetsingskader om te bepalen of er voor kinderen een medische noodtoestand ontstaat bij terugkeer. Ook wordt het hebben van een handicap niet als reden gezien om een asielvergunning te verlenen. De verblijfsrechtelijke procedures nemen veel tijd in beslag, waardoor de kinderen lange tijd in grote onzekerheid zitten. Dit heeft een negatieve invloed op hun gezondheid. De gezondheid van kinderen lijdt onder het verblijf in een asielzoekerscentrum of vrijheidsbeperkende gezinslocatie. De locaties zijn te druk en lawaaiig. Sommige kinderen kunnen als gevolg van hun verblijf in een asielzoekerscentrum niet de zorg krijgen die behandelaars nodig vinden. Soms wordt de situatie zorgelijk geacht voor hun gezondheid. Kinderen met een handicap zou tijdens de procedure passende woonruimte aangeboden moeten worden, bij voorkeur buiten een asielzoekerscentrum, om aanvullende stress te voorkomen.

De toegang tot gezondheidszorg voor kinderen met een handicap is onvoldoende gegarandeerd. De Kinderombudsman heeft de minister van Justitie en Veiligheid aanbevolen om samen met andere organisaties voor gezondheidszorg en vreemdelingenrecht een richtlijn op te stellen voor de zorg voor kinderen die (nog) geen verblijfsvergunning hebben. Defence for Children onderschrijft die aanbeveling van harte. Daarbij mag geen onderscheid worden gemaakt tussen de zorg voor kinderen met of zonder verblijfsrecht. Ook moet er altijd een goede belangenafweging worden gemaakt, waarbij de belangen van het kind en andere belangen apart in kaart worden gebracht en de belangen van het kind zwaarwegend zijn. De kinderen mogen niet verder worden beschadigd door de procedures en opvang. Zij hebben recht op extra bescherming. 